\title{
Comparison of the cuff pressure of TaperGuard endotracheal tube and cylindrical endotracheal tube after lateral rotation of head during middle ear surgery: A single blind randomized study
}

\author{
Hyeonjun Lee, Younghoon Jeon
}

Department of Anesthesiology and Pain Medicine, Kyungpook National University Hospital, Daegu, south Korea

\section{Background}

Positional change affects the cuff pressure of endotracheal tube (ETT) in treacheally intubated patients.

We compared the cuff pressure of TaperGuard ETT and cylindrical ETT after lateral rotation of head during middle ear surgery.

\section{Methods}

Fifty two patients aged 18-70 years underwent tympanomastoidectomy under general anesthesia

Group C ( $\mathrm{n}=26)$ intubated with cylindrical ETT Group T $(n=25)$ intubated with TaperGuard ETT

After endotracheal intubation,

ETT cuff pressure was set at $22 \mathrm{cmH}_{2} \mathrm{O}$ in the neutral position of head.

After lateral rotation of head

Cuff pressure was measured again and readjusted to 22 $\mathrm{cmH}_{2} \mathrm{O}$.

Change of distance from the carina to the tip of ETT was measured before and after positional change.

Student's $t$ test, chi-squared test, or Fisher's exact test, as appropriate. $P<0.05$ was considered statistically significant. Data were expressed as mean \pm SD or number (\%).(Figure 1.).

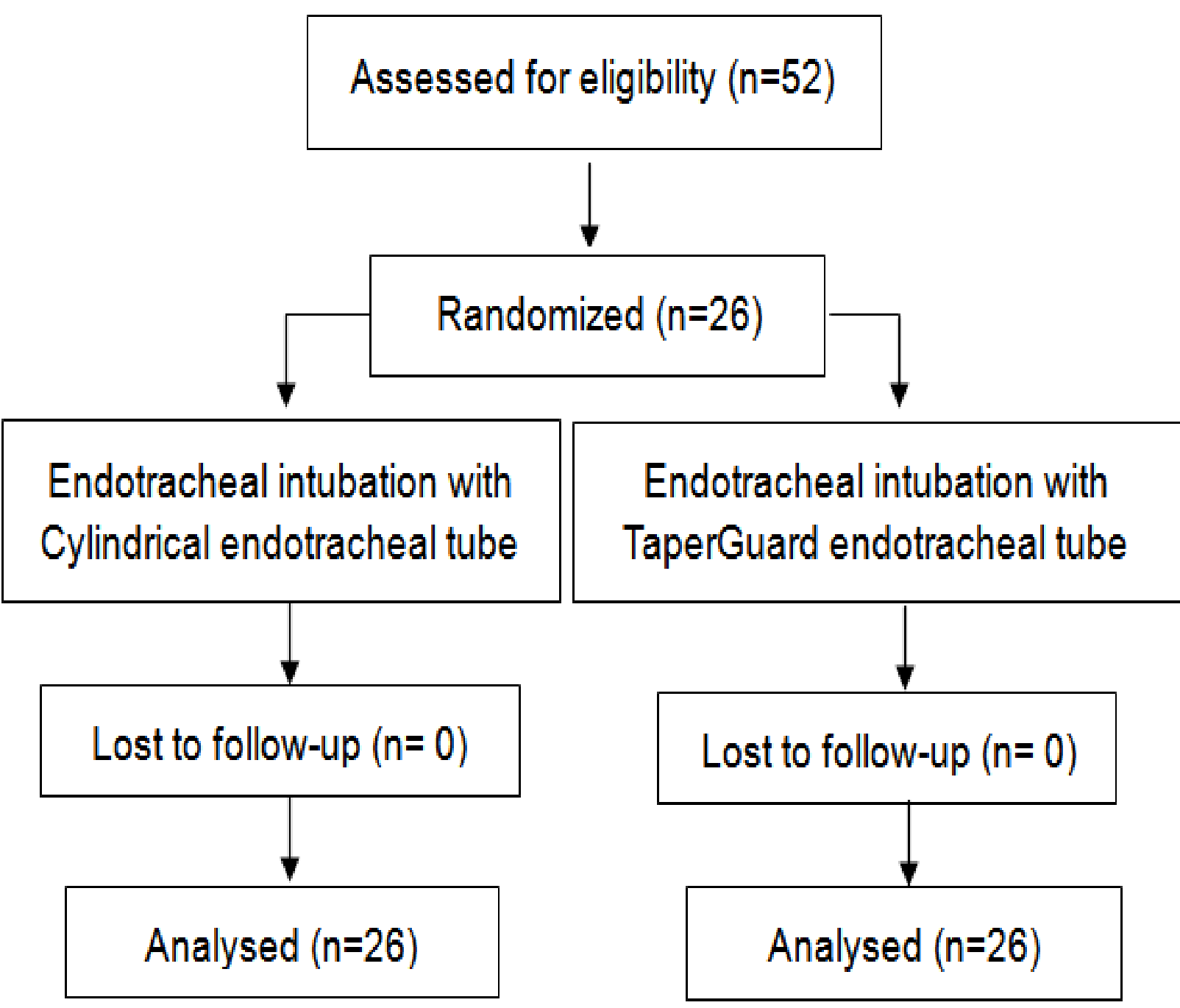

Figure 1. Flow diagram of the study

\section{Results}

Table 1

Patient characteristics and intraoperative data.

\begin{tabular}{lcc}
\hline & \multicolumn{2}{c}{ Group } \\
\cline { 2 - 3 } Characteristics & Group $\mathbf{T}(\mathbf{n}=\mathbf{2 6})$ & Group $\mathbf{C}(\mathbf{n = 2 6})$ \\
\hline Age, $\mathrm{y}$ & $53.4 \pm 11.0$ & $52.3 \pm 16.7$ \\
Sex (M/F) & $13 / 13$ & $9 / 17$ \\
Weight, $\mathrm{kg}$ & $64.3 \pm 9.4$ & $60.0 \pm 9.8$ \\
Height, $\mathrm{Cm}$ & $163.2 \pm 7.7$ & $161.6 \pm 8.6$ \\
Body mass index, $\mathrm{kg} / \mathrm{m}^{2}$ & $24.0 \pm 1.9$ & $22.9 \pm 2.6$ \\
Duration of surgery, min & $140.8 \pm 64.1$ & $142.5 \pm 72.6$ \\
Duration of anesthesia, min & $162.3 \pm 66.1$ & $164.0 \pm 72.4$ \\
Lateral rotation of head, $\mathrm{n}$ & $14 / 12$ & $13 / 13$ \\
Left/Right & & \\
\hline
\end{tabular}

Values are presented as either mean \pm standard deviation or number.

Group $\mathrm{T}=$ TaperGuard endotracheal tube; Group $\mathrm{C}=$ cylindrical endotracheal tube.

\section{Table 2}

Cuff pressure and withdrawal of a tracheal tube after a positional change of head from neutral to lateral rotation.

\begin{tabular}{lcc}
\hline & \multicolumn{2}{c}{ Group } \\
\cline { 2 - 3 } & Group $\mathbf{T}(\mathbf{n}=\mathbf{2 6})$ & Group $\mathbf{C}(\mathbf{n}=\mathbf{2 6})$ \\
\hline Cuff pressure, $\mathrm{CmH}_{2} \mathrm{O}$ & $33.7 \pm 2.4^{*}$ & $28.0 \pm 1.9$ \\
Difference of cuff pressure, $\mathrm{CmH}_{2} \mathrm{O}$ & $11.9 \pm 2.3^{*}$ & $6.0 \pm 1.9$ \\
Withdrawal of tube, $\mathrm{mm}$ & $11.0 \pm 1.7^{*}$ & $7.2 \pm 2.6$ \\
\hline
\end{tabular}

Values are presented as mean \pm standard deviation.

Group $T=$ TaperGuard endotracheal tube; Group $C=$ cylindrical endotracheal tube.

"Statistically significant difference between group $T$ and $C(P<0.001)$.

\section{Table 3}

The cuff pressure $>30 \mathrm{cmH}_{2} \mathrm{O}$ in lateral rotation of head.

\begin{tabular}{lcc}
\hline & \multicolumn{2}{c}{ Group } \\
\cline { 2 - 3 } Lateral rotation of head & Group T $(\mathbf{n}=26)$ & Group C $(\mathbf{n}=26)$ \\
\hline Left & $13(50 \%)^{*}$ & $4(15.4 \%)$ \\
Right & $12(46.2 \%)^{*}$ & $4(15.4 \%)$ \\
Total & $25(96.2 \%)^{*}$ & $8(30.8 \%)$ \\
\hline
\end{tabular}

Values are presented as number $(\%)$.

Group $T=$ TaperGuard endotracheal tube; Group $C=$ cylindrical endotracheal tube.

${ }^{*}$ Statistically significant difference between group $T$ and $C(P<0.05)$.

\section{Conclusions}

After lateral rotation of head the cuff pressure was higher in TaperGuard ETT than in cylindrical ETT. The extent of displacement of ETT was greater in TaperGuard ETT than in cylindrical ETT. 